Article

\title{
Characterization of Poly(Ethylene Oxide) Nanofibers-Mutual Relations between Mean Diameter of Electrospun Nanofibers and Solution Characteristics ${ }^{\dagger}$
}

\author{
Petr Filip * and Petra Peer(D) \\ Institute of Hydrodynamics of the Czech Academy of Sciences, 16000 Prague, Czech Republic; peer@ih.cas.cz \\ * Correspondence: filip@ih.cas.cz \\ † This paper is an expanded version of "Electrospinning of poly(ethylene oxide) solutions-Quantitative \\ relations between mean nanofibre diameter, concentration, molecular weight, and viscosity " published in \\ Proceedings of Novel Trends in Rheology VIII, Zlin, Czech Republic, 30-31 July 2019.
}

Received: 11 November 2019; Accepted: 2 December 2019; Published: 12 December 2019

\begin{abstract}
The quality of electrospun poly(ethylene oxide) (PEO) nanofibrous mats are subject to a variety of input parameters. In this study, three parameters were chosen: molecular weight of PEO $(100,300,600$, and $1000 \mathrm{~kg} / \mathrm{mol}), \mathrm{PEO}$ concentration (in distilled water), and shear viscosity of PEO solution. Two relations free of any adjustable parameters were derived. The first, describing the initial stage of an electrospinning process expressing shear viscosity using PEO molecular weight and concentration. The second, expressing mean nanofiber diameter using concentration and PEO molecular weight. Based on these simple mathematical relations, it is possible to control the mean nanofiber diameter during an electrospinning process.
\end{abstract}

Keywords: electrospinning; poly(ethylene oxide); nanofiber diameter; molecular weight; concentration

\section{Introduction}

At present, nanofibrous mats are efficiently used in many applications: filters, tissue engineering, drug delivery systems, antibacterial wound dressing, protective clothing, nanocomposite materials, to name a few. One of the ways one can produce nanofibrous mats is through the process of electrospinning. In this process, polymer solution or melt is exposed to a high-voltage electric field (in orders of tens $\mathrm{kV}$ ) under which viscoelastic polymer jets emanate from so-called Taylor cones [1] formed at the polymer surface. After passing approximately $10-20 \mathrm{~cm}$ in length, the material of the jets (after evaporation of a solvent) is cumulated on an earthed collector [2-4] at the shape of individual nanofibers forming a non-woven textile.

The problem is that some promising materials, such as chitosan, keratin, and other protein-based materials, cannot be electrospun in their pure forms. This contrasts with the easy spinnability $[5,6]$ of, e.g., poly(ethylene oxide) (PEO). Fortunately, even the negligible presence of PEO (up to $2 \%$ ) in solutions of the above-listed materials completely changes their disposition to being electrospun (see below). Intensive study of PEO behavior during the electrospinning process has been undertaken due to this fact and because of the excellent biodegradability, biocompatibility, and non-toxicity. These attributes also reflect PEO nanofiber applications in biomedicine and the food industry [7-10] apart from the above already mentioned improvements in spinnability in combination with chitin or chitosan [11-14], keratin [15,16], silk [17,18] and other materials. 
As in any electrospun material the resulting properties of PEO nanofibrous mats are subject to four groups of entry parameters: the polymer (molecular weight, molecular weight distribution, topology of macromolecules), solvent (surface tension, solubility parameters, relative permittivity), solution (viscosity, concentration, specific conductivity), and process parameters (electric field strength, tip-to-collector distance, temperature, humidity). In no way can these parameters be analyzed separately as many of them are mutually interlaced as can be documented, for example, in the case of molecular weight, concentration, and viscosity.

The whole process of electrospinning is so complex that there is no possibility to express the behavior of one parameter-e.g., a mean nanofiber diameter-through the remaining ones. This can be documented by a relatively complicated process of nanofiber formation starting from an initial straightforward stable motion of liquid material towards a collector, consecutively changed to a 'whipping' (unstable, chaotic) motion, and finally, after solvent evaporation, converting to solid nanofibers. Therefore, there is a necessity to choose a limited number of crucial parameters that participate in the setting of a nanofiber diameter and fixing of the others.

Experimentally this approach was applied to determine the dependence of a mean nanofiber diameter on polymer concentration [19-28], on applied voltage [22-26,28,29], on viscosity [20,21], on solution flow rate $[22,23,25,26,29]$, on tip-to-collector distance [22-24,30], on addition of salts [24,29], on the composition of the mixed solvent [31], on elasticity of the solution [32], on addition of nanoparticles [33,34], on addition of polyelectrolyte [35].

Electrospinning is a complex phenomenon to analyze because of the coupling between the electric field and the deformation of the fluid, the latter, in turn, determined by the rheology of the material [36]. The first theoretical approach in describing the process where electrospinning starts with a Taylor cone, passes through both regions (straightforward and spiraling) of viscoelastic jet, and then up to the deposition of nanofibers onto a collector, appeared approximately two decades ago. The beads-spring model (not to be confused with the appearance of unwanted beads violating the straight geometry of final nanofibers) was presented in [37]. A list of this and other models [38-46] describing the flow behavior of electrified and electrospun viscoelastic jets is introduced in [2].

The authors in [44] concluded that a final nanofiber diameter can be determined from knowledge of the flow rate, electric current, and the surface tension of the fluid. In [27], the authors present the independence of an initial straight jet diameter on solution concentration and indicate that a mean nanofiber diameter depends dominantly on the jet-whipping process. In [47], the authors applied the theoretical modeling in $[42,43]$ and stated that the final diameter also depends on the initial diameter of a jet. They classify the importance of 13 entry parameters with respect to their influence on a mean nanofiber diameter and sort them into three groups: strong, moderate, and minor. The model involving solution viscosity, evaporation rate, and containing specific charge (electric current divided by the spinning throughput) was introduced in [48,49]. A prediction of a final nanofiber diameter published in [50] is based on the model published in [36]. However, the assumptions limit the model to relatively low polymer-solvent concentrations $(<12 \mathrm{wt}$.\%). A determination of the final nanofiber diameter considers solution flow rate, applied voltage, and polymer concentration.

Applicability of the electrospun nanofibrous mats (filters, membranes, etc.) is closely related to their permeability. Hence, the passage of the particles through the mats can also be controlled by molecular weight and concentration of a polymeric material used in the process of electrospinning. The standard experiments providing mean nanofiber diameters and shear viscosity dependent on molecular weights and used concentrations of polymeric material are time-consuming, with higher financial costs and cover only discrete values of entry parameters.

This contribution aims to propose the relations mutually relating three entry parameters (PEO molecular weight, PEO concentration, shear viscosity of PEO solution) and a resulting mean nanofiber diameter. In contrast to the experiments, these relations cover continuously and sufficiently broad regions of entry parameters creating the possibility of achieving a required mean nanofiber diameter. 
The proposed relations are compared with the experiments (four various PEO molecular weights), and the mean deviations are practically within the experimental errors.

\section{Materials and Methods}

\subsection{Materials}

Four various poly (ethylene oxide) (Sigma Aldrich, Saint Louis, MO, USA) batches differing in molecular weight $(100,300,600$, and $1000 \mathrm{~kg} / \mathrm{mol})$ were consecutively dissolved in distilled water at different concentration ranges (introduced in Table 1) meeting successful spinnability (subjected to a molecular weight) of the PEO solutions. The PEO solutions were prepared using a magnetic stirrer (Heidolph MR Hei-Tec, Schwabach, Germany) with the help of a Teflon-coated magnetic cross applied for $48 \mathrm{~h}$ under constant conditions (mixing rate $250 \mathrm{rpm}$ and temperature $25^{\circ} \mathrm{C}$ ).

Table 1. A list of prepared poly(ethylene oxide) (PEO) solutions.

\begin{tabular}{cc}
\hline Molecular Weight (kg/mol) & Concentration (wt.\%) \\
\hline 100 & $12,15,20,22,24,28,30,34$ \\
300 & $5,7,8,9,10,11,12,13,15,17$ \\
600 & $3,5,5.4,6,7,8,9$ \\
1000 & $3,3.3,3.75,4,5,6$ \\
\hline
\end{tabular}

\subsection{Rheological Characterization}

Shear viscosity of the individual PEO solutions was determined at a constant temperature of 25 ${ }^{\circ} \mathrm{C}$ using a Physica MCR 501 device (Anton Paar, Graz, Austria) equipped with concentric cylinders (26.6/28.9 mm-inner/outer diameters). Each measurement was repeated at least three times with very good reproducibility.

\subsection{The Electrospinning Process}

Laboratory equipment consisting of a high voltage power supply (Spellman SL70PN150, Hauppauge, NY, USA), a carbon steel stick (10 $\mathrm{mm}$ in diameter) with a hollowed semi-spherical pit at the end for polymer filling, and equipped with a motionless flat metal collector (for details see [51]) was used for an electrospinning process. The drop of polymer solution filling the pit contains approximately $0.2 \mathrm{~mL}$ in volume, a tip-to-collector distance was fixed $(20 \mathrm{~cm})$ as well as nearly constant ambient conditions (temperature $23 \pm 1{ }^{\circ} \mathrm{C}$, relative humidity $41 \pm 1 \%$ ). Good quality of electrospun mats (elimination of appearance of web blobs) was ensured by a gradual voltage decrease from $25 \mathrm{kV}$ fixed for $M_{\mathrm{w}}=100 \mathrm{~kg} / \mathrm{mol}$ to $12 \mathrm{kV}$ fixed for $M_{\mathrm{w}}=1000 \mathrm{~kg} / \mathrm{mol}$.

\subsection{Nanofibrous Mat Characterization}

A high-resolution scanning electron microscope (SEM) Vega 3 (Tescan, Brno, Czech Republic) was used for imaging of nanofibrous mats after their sputtering with a conductive layer to improve conductivity.

\section{Results and Discussion}

Due to a non-negligible number of entry parameters, the process of electrospinning cannot be simultaneously analyzed from all material, geometrical, and process aspects. It is always necessary to fix a substantial majority of entry parameters and concentrate on a moderate number of selected parameters. The impacts of the individual parameters are usually interlaced, and in the following analysis, we will pay attention to a mutual interplay between PEO molecular weight, PEO concentration, viscosity of a PEO solution in distilled water, and a mean diameter of the resulting nanofibers.

Specifically, the emphasis will focus on the derivation of two dependencies: 
(1) A determination of functional relation between shear viscosity $(\eta)$, PEO concentration $(c)$, and PEO molecular weight $\left(M_{\mathrm{w}}\right)$;

(2) A determination of functional relation between the diameter of nanofibers (dia), PEO concentration $(c)$, and PEO molecular weight $\left(M_{\mathrm{W}}\right)$.

From the viewpoint of easy and clear applicability of the proposed relations, they should exhibit the following attributes:

(a) Usage of elementary algebraic functions only;

(b) Absence of adjustable parameters;

(c) Their validity should cover sufficiently broad regions of two entry material characteristics-PEO molecular weight and PEO concentrations in distilled water (a range of concentrations shifts with respect to successful electrospinability of PEO solutions dependent on $M_{\mathrm{w}}$ );

(d) The correctness of the approximate relations-deviations of their predictions from the experimental data should potentially exceed the experimental errors only moderately.

The least accurate determination of a precise value out of the four studied parameters $\left(M_{\mathrm{w}}, c, \eta\right.$, dia) is represented by the mean nanofiber diameter dia.

A mean nanofiber diameter derived from 300 measurements taken from three different images was determined by applying the Adobe Creative Suite software (San Jose, CA, USA). Figure 1 displays SEM images of PEO nanofibers created from various molecular weights at different concentrations. The histograms attached to the individual molecular weights depict a variance of nanofiber diameters. This is also documented in Table 2.
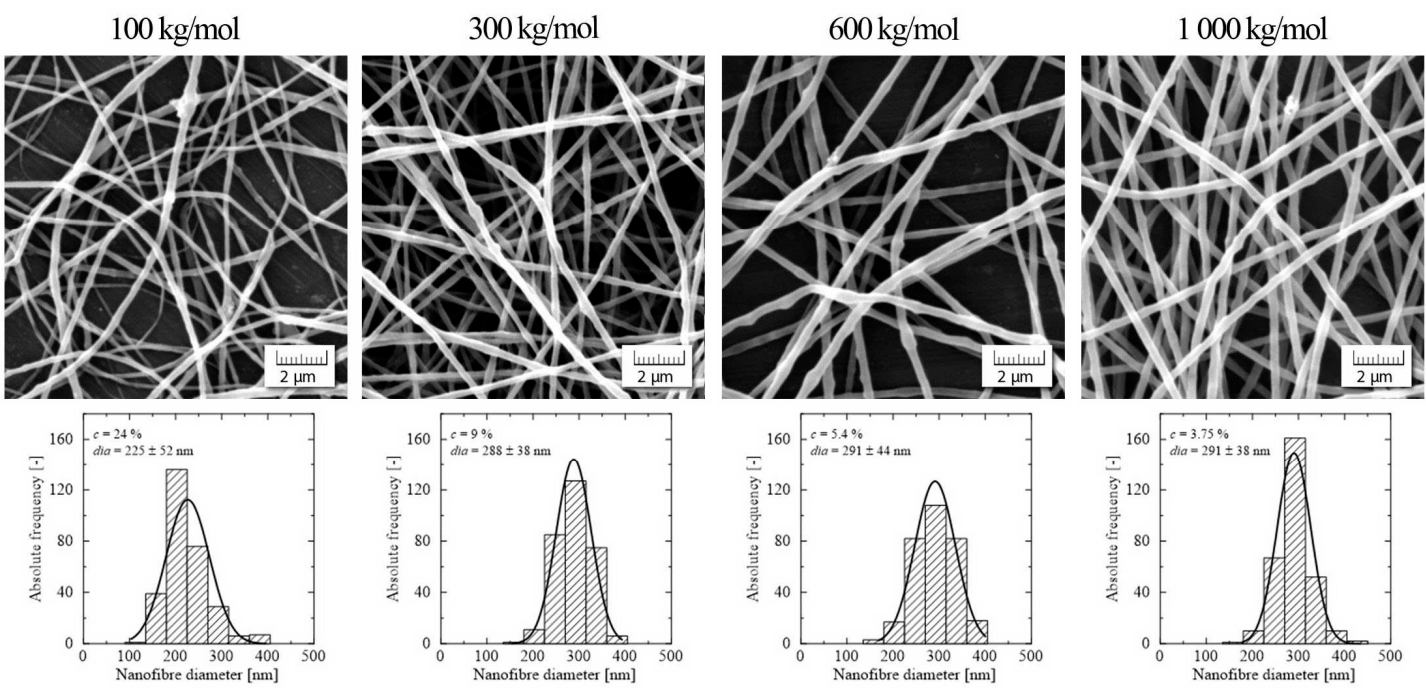

Figure 1. SEM pictures of nanofibrous mats for different poly(ethylene oxide) (PEO) solutions: $M_{\mathrm{w}}=$ $100 \mathrm{~kg} / \mathrm{mol}, c=24 \% ; M_{\mathrm{W}}=300 \mathrm{~kg} / \mathrm{mol}, c=9 \% ; M_{\mathrm{W}}=600 \mathrm{~kg} / \mathrm{mol}, c=5.4 \% ; M_{\mathrm{W}}=1,000 \mathrm{~kg} / \mathrm{mol}, c=$ $3.75 \%$. The corresponding histograms describe the variance of nanofiber diameters.

Table 2. Variance of the measured nanofiber diameters.

\begin{tabular}{|c|c|c|c|c|c|c|c|c|c|c|c|}
\hline$M_{\mathrm{w}}(\mathrm{kg} / \mathrm{mol})$ & & & & & ispersion & f Nanofib & r Diamete & & & & \\
\hline \multirow{2}{*}{100} & $c(\mathrm{wt} . \%)$ & 12 & 15 & 20 & 22 & 24 & 28 & 30 & 34 & & \\
\hline & dia $(\mathrm{nm})$ & $113 \pm 34$ & $147 \pm 33$ & $174 \pm 52$ & $206 \pm 49$ & $225 \pm 52$ & $279 \pm 56$ & $303 \pm 40$ & $326 \pm 43$ & & \\
\hline \multirow{2}{*}{300} & $c(w t . \%)$ & 5 & 7 & 8 & 9 & 10 & 11 & 12 & 13 & 15 & 17 \\
\hline & dia $(\mathrm{nm})$ & $132 \pm 26$ & $210 \pm 46$ & $237 \pm 44$ & $288 \pm 38$ & $305 \pm 48$ & $326 \pm 41$ & $344 \pm 47$ & $367 \pm 42$ & $389 \pm 53$ & $442 \pm 46$ \\
\hline \multirow{2}{*}{600} & $c($ wt.\%) & 3 & 5 & 5.4 & 6 & 7 & 8 & 9 & & & \\
\hline & dia $(\mathrm{nm})$ & $141 \pm 30$ & $267 \pm 42$ & $291 \pm 44$ & $310 \pm 44$ & $331 \pm 43$ & $389 \pm 28$ & $430 \pm 46$ & & & \\
\hline \multirow{2}{*}{1000} & $c(w t . \%)$ & 3 & 3.3 & 3.75 & 4 & 5 & 6 & & & & \\
\hline & dia $(\mathrm{nm})$ & $206 \pm 35$ & $265 \pm 29$ & $291 \pm 38$ & $308 \pm 49$ & $391 \pm 52$ & $513 \pm 75$ & & & & \\
\hline
\end{tabular}


After analyzing and processing the experimental data obtained by consecutive electrospinning of PEO solutions differing in PEO molecular weight $(100,300,600$, and $1000 \mathrm{~kg} / \mathrm{mol})$ and concentration (see Table 2), we can calculate the correlation coefficients for the experimental data sets (c, dia). Their proximity to one (pure linearity behavior, see Table 3 ) indicates the possibility to approximate a mutual dependence of the mean nanofiber diameter on the concentration by a simple linear relation. To unify this approach, it is also necessary to express a general coefficient of linearity through the values of PEO molecular weights, which results in a slight deviation from the optimized values for the individual molecular weights.

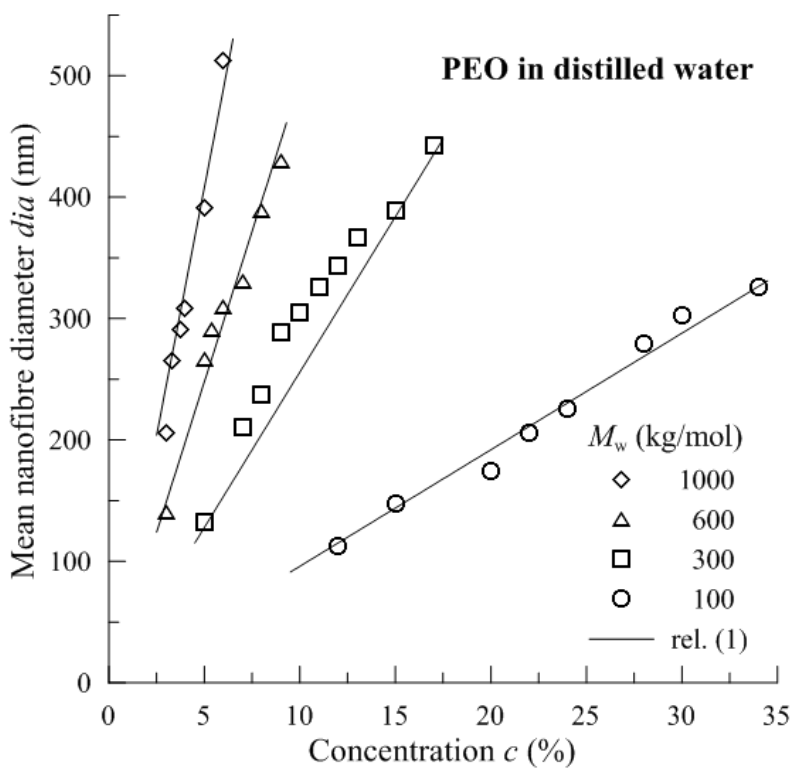

Figure 2. Dependence of mean nanofiber diameter (dia) on concentration (c) and molecular weight $\left(M_{\mathrm{W}}\right)$.

Table 3. Correlation coefficients between $(c, d i a)$ and $(\log (c), \log (\eta))$.

\begin{tabular}{ccc}
\hline $\boldsymbol{M}_{\mathbf{w}}(\mathbf{k g} / \mathbf{m o l})$ & \multicolumn{2}{c}{ Correlation Coefficient $[-]$} \\
\hline & $(c$, dia $)$ Figure 2 & $(\log (c), \log (\eta))$ Figure 4 \\
100 & 0.992 & 0.996 \\
300 & 0.980 & 0.998 \\
600 & 0.987 & 0.997 \\
1000 & 0.992 & 0.942 \\
\hline
\end{tabular}

Finally, we propose the following relation

$$
d i a=\left(\mathrm{a}_{1} M_{\mathrm{w}}+\mathrm{a}_{2}\right) \times \mathrm{c}
$$

with a linear proportionality between the mean nanofiber diameter and concentration, and with a linear dependence between the mean nanofiber diameter and molecular weight. The numerical values of the constants are $\mathrm{a}_{1}=0.00008$ and $\mathrm{a}_{2}=1.6$. The correspondence between the experimental and predicted data is depicted in Figure 2, with the mean deviation attaining 6.7\%. Relation (1) complies with the tendencies introduced in literature [52,53], i.e., an increase in the nanofiber diameter both with increasing molecular weight and increasing concentration.

Dependence between shear viscosity, molecular weight, and concentration is a little more complicated. If we apply an analogous approach to that above, we obtain the correlation coefficients for the data sets $(\log (c), \log (\eta))$, again in close proximity to one (see Table 3$)$. It justifies the proposal of 
a linear relation between $\log (c)$ and $\log (\eta)$. Unifying both a slope and an intercept with respect to the range of PEO molecular weights, a proposed relation is still algebraically simple.

$$
\log (\eta)=b_{1} \times \log (c)+\left[b_{2} \times\left(\log \left(M_{\mathrm{W}}\right)\right)^{2}+b_{3} \times \log \left(M_{\mathrm{W}}\right)+b_{4}\right],
$$

where $b_{1}=4.71, b_{2}=-0.82, b_{3}=12.7, b_{4}=-48.8$. As can be seen, Relation (2) is composed of two separate members, the first one expressing a contribution of concentration only and the second one (in brackets) representing the participation of molecular weight exclusively. Figure 3 documents the courses of the proposed predicted curves attaining a mean deviation of $6.3 \%$ in the semi-log coordinates (concentration-linear, shear viscosity-logarithmic), in fully linear coordinates, a mean deviation attained $11.8 \%$. In the $\log -\log$ coordinates (Figure 4), there is a linear dependence of shear viscosity on PEO concentration with the fixed slope attaining a value of 4.71 .

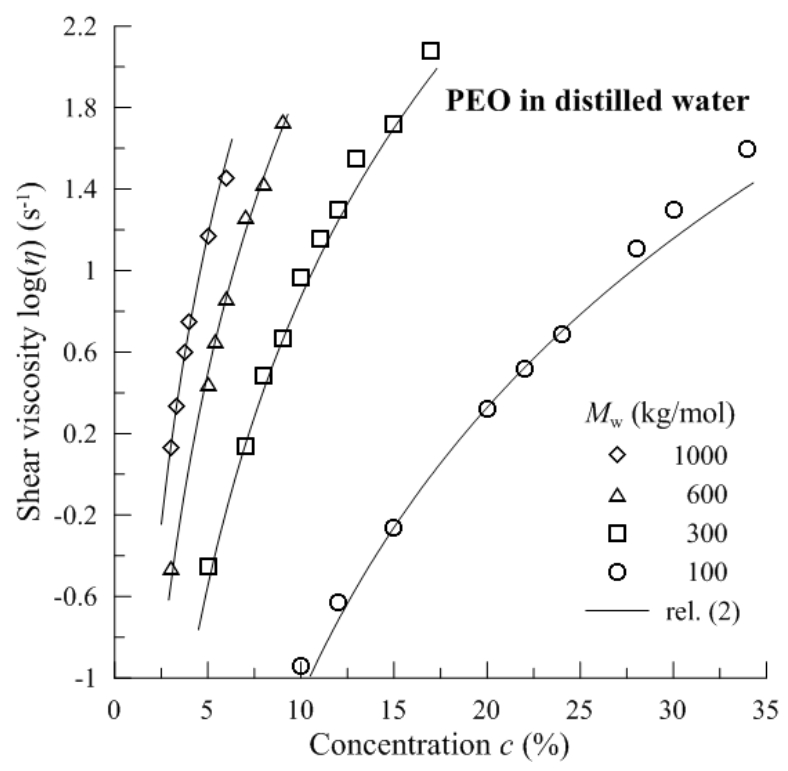

Figure 3. Dependence of shear viscosity $(\log (\eta))$ on concentration $(c)$ and molecular weight $\left(M_{\mathrm{w}}\right)$ in semi-log coordinates.

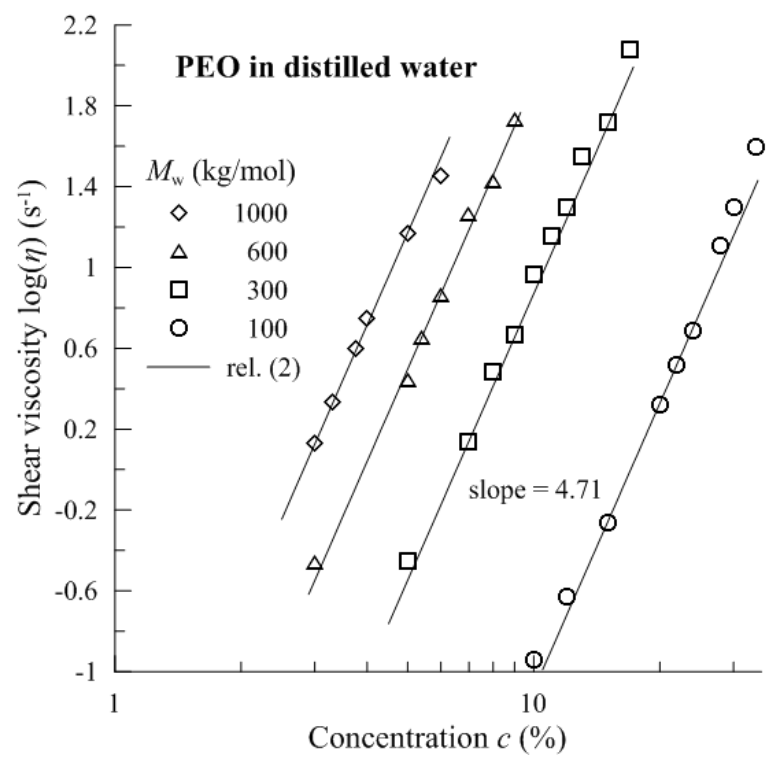

Figure 4. Dependence of shear viscosity $(\log (\eta))$ on concentration $(c)$ and molecular weight $\left(M_{\mathrm{w}}\right)$ in $\log$-log coordinates. 


\section{Conclusions}

The introduced relationships propose a hint as to which way the geometrical arrangement of the resulting electrospun nanofibrous mats can be modified. Based on the relatively simple functional Relation (1), it is possible to alter a mean nanofiber diameter by a suitable choice of PEO material (choice of an adequate molecular weight) and setting a corresponding concentration. Relation (2) characterizes the mutual interplay between three input parameters: molecular weight, concentration, and shear viscosity. Both Relations (1) and (2) are valid for the processed material-PEO-solved in distilled water. However, it can be expected that the analogous relations could also be derived for other combinations of polymers and solvents.

Author Contributions: Investigation, P.F. and P.P.; Writing, P.F.

Funding: This research was funded by the Grant Agency CR, grant number 17-26808S.

Conflicts of Interest: The authors declare no conflict of interest.

\section{References}

1. Taylor, G.I. Electrically driven jets. Proc. R. Soc. A 1969, 313, 453-475. [CrossRef]

2. Reneker, D.H.; Yarin, A.L. Electrospinning jets and polymer nanofibers. Polymer 2008, 49, 2387-2425. [CrossRef]

3. Bhardwaj, N.; Kundu, S.C. Electrospinning: A fascinating fiber fabrication technique. Biotechnol. Adv. 2010, 28, 325-347. [CrossRef] [PubMed]

4. Agarwal, S.; Greiner, A.; Wendorff, J.H. Functional materials by electrospinning of polymers. Prog. Polym. Sci. 2013, 38, 963-991. [CrossRef]

5. Deitzel, J.M.; Kleinmeyer, J.D.; Hirvonen, J.K.; Tan, N.C.B. Controlled deposition of electrospun poly (ethylene oxide) fibers. Polymer 2001, 42, 8163-8170. [CrossRef]

6. Son, W.K.; Youk, J.H.; Lee, T.S.; Park, W.H. The effects of solution properties and polyelectrolyte on electrospinning of ultrafine poly (ethylene oxide) fibers. Polymer 2004, 45, 2959-2966. [CrossRef]

7. Agarwal, S.; Wendorff, J.H.; Greiner, A. Use of electrospinning technique for biomedical applications. Polymer 2008, 49, 5603-5621. [CrossRef]

8. Rieger, K.A.; Birch, N.P.; Schiffman, J.D. Designing electrospun nanofiber mats to promote wound healing-A review. J. Mater. Chem. B 2013, 1, 4531-4541. [CrossRef]

9. Chew, S.Y.; Wen, Y.; Dzenis, Y.; Leong, K.W. The role of electrospinning in the emerging field of nanomedicine. Curr. Pharm. Des. 2006, 12, 4751-4770. [CrossRef]

10. Heunis, T.; Bshena, O.; Klumperman, B.; Dicks, L. Release of bacteriocins from nanofibers prepared with combinations of poly (D, L-lactide) (PDLLA) and poly (ethylene oxide) (PEO). Int. J. Mol. Sci. 2011, 12, 2158-2173. [CrossRef]

11. Jung, H.-S.; Kim, M.H.; Shin, J.Y.; Park, S.R.; Jung, J.-Y.; Park, W.H. Electrospinning and wound healing activity of $\beta$-chitin extracted from cuttlefish bone. Carbohydr. Polym. 2018, 193, 205-211. [CrossRef]

12. Kuntzler, S.G.; Vieira Costa, J.A.; de Morais, M.G. Development of electrospun nanofibers containing chitosan/PEO blend and phenolic compounds with antibacterial activity. Int. J. Biol. Macromol. 2018, 117, 800-806. [CrossRef] [PubMed]

13. Garcia, C.E.G.; Martínez, F.A.S.; Bossard, F.; Rinaudo, M. Biomaterials Based on Electrospun Chitosan. Relation between Processing Conditions and Mechanical Properties. Polymers 2018, 10, 257. [CrossRef] [PubMed]

14. Abid, S.; Hussain, T.; Nazir, A.; Zahir, A.; Ramakrishna, S.; Hameed, M.; Khenoussi, N. Enhanced antibacterial activity of PEO-chitosan nanofibers with potential application in burn infection management. Int. J. Biol. Macromol. 2019, 135, 1222-1236. [CrossRef] [PubMed]

15. Aluigi, A.; Vineis, C.; Varesano, A.; Mazzuchetti, G.; Ferrero, F.; Tonin, C. Structure and properties of keratin/PEO blend nanofibres. Europ. Polym. J. 2008, 44, 2465-2475. [CrossRef]

16. Ma, H.; Shen, J.; Cao, J.; Wang, D.; Yue, B.; Mao, Z.; Wu, W.; Zhang, H. Fabrication of wool keratin/polyethylene oxide nano-membrane from wool fabric waste. J. Clean. Prod. 2017, 161, 357-361. [CrossRef] 
17. Jin, H.J.; Fridrikh, S.V.; Rutledge, G.C.; Kaplan, D.L. Electrospinning Bombyx mori silk with poly (ethylene oxide). Biomacromolecules 2002, 3, 1233-1239. [CrossRef]

18. Wharram, S.E.; Zhang, X.; Kaplan, D.L.; McCarthy, S.P. Electrospun silk material systems for wound healing. Macromol. Biosci. 2010, 10, 246-257. [CrossRef]

19. Deitzel, J.M.; Kleinmeyer, J.; Harris, D.; Tan, N.C.B. The effect of processing variables on the morphology of electrospun nanofibers and textiles. Polymer 2001, 42, 261-272. [CrossRef]

20. McKee, M.G.; Wilkes, G.L.; Colby, R.H.; Long, T.E. Correlations of Solution Rheology with Electrospun Fiber Formation of Linear and Branched Polyesters. Macromolecules 2004, 37, 1760-1767. [CrossRef]

21. Gupta, P.; Elkins, C.; Long, T.E.; Wilkes, G.L. Electrospinning of linear homopolymers of poly (methyl methacrylate): Exploring relationships between fiber formation, viscosity, molecular weight and concentration in a good solvent. Polymer 2005, 46, 4799-4810. [CrossRef]

22. Chowdhury, M.; Stylios, G.K. Analysis of the effect of experimental parameters on the morphology of electrospun polyethylene oxide nanofibres and on their thermal properties. J. Text. Inst. 2012, 103, 124-138. [CrossRef]

23. Kong, L.; Ziegler, G.R. Quantitative relationship between electrospinning parameters and starch fiber diameter. Carbohydr. Polym. 2013, 92, 1416-1422. [CrossRef] [PubMed]

24. Matabola, K.P.; Moutloali, R.M. The influence of electrospinning parameters on the morphology and diameter of poly (vinyledene fluoride) nanofibers-effect of sodium chloride. J. Mater. Sci. 2013, 48, 5475-5482. [CrossRef]

25. Ghorani, B.; Goswami, P.; Russell, S.J. Parametric Study of Electrospun Cellulose Acetate in Relation to Fibre Diameter. Res. J. Text. Appar. 2015, 19, 24-40. [CrossRef]

26. Şimşek, M.; Çakmak, S.; Gümüşderelioğlu, M. Insoluble poly (ethylene oxide) nanofibrous coating materials: Effects of crosslinking conditions on the matrix stability. J. Polym. Res. 2016, 23, 236. [CrossRef]

27. Wang, C.; Wang, Y.; Hashimoto, T. Impact of entanglement density on solution electrospinning: A phenomenological model for fiber diameter. Macromolecules 2016, 49, 7985-7996. [CrossRef]

28. Lasprilla-Botero, J.; Alvarez-Lainez, M.; Lagaron, J.M. The influence of electrospinning parameters and solvent selection on the morphology and diameter of polyimide nanofibers. Mater. Today Commun. 2018, 14, 1-9. [CrossRef]

29. Zong, X.; Kim, K.; Fang, D.; Ran, S.; Hsiao, B.S.; Chu, B. Structure and process relationship of electrospun bioabsorbable nanofiber membranes. Polymer 2002, 43, 4403-4412. [CrossRef]

30. Long, F.C.; Kamsom, R.A.; Nurfaizey, A.H.; Isa, M.H.M.; Masripan, N.A.B. The influence of electrospinning distances on fibre diameter of poly (vinyl alcohol) electrospun nanofibers. In Proceedings of the 4th Mechanical Engineering Research Day (MERD), University Teknikal Malaysia Melaka, Melaka, Malaysia, 30 March 2017; Bin Abdollah, M.F., Tuan, T.B., Salim, M.A., Akop, M.Z., Ismail, R., Musa, H., Eds.; pp. 377-378.

31. Han, S.O.; Youk, J.H.; Min, K.D.; Kang, Y.O.; Park, W.H. Electrospinning of cellulose acetate nanofibers using a mixed solvent of acetic acid/water: Effects of solvent composition on fiber diameter. Mater. Lett. 2008, 62, 759-762. [CrossRef]

32. Gupta, D.; Jassal, M.; Agrawal, A.K. Electrospinning of poly (vinyl alcohol)-based Boger fluids to understand the role of elasticity on morphology of nanofibres. Ind. Eng. Chem. Res. 2015, 54, 1547-1554. [CrossRef]

33. Sundarrajan, S.; Ramakrishna, S. Fabrication of nanocomposite membranes from nanofibers and nanoparticles for protection against chemical warfare stimulants. J. Mater. Sci. 2007, 42, 8400-8407. [CrossRef]

34. Yang, Q.B.; Li, D.M.; Hong, Y.L.; Li, Z.Y.; Wang, C.; Qiu, S.L.; Wei, Y. Preparation and characterization of a PAN nanofiber containing Ag nanoparticles via electrospinning. Synth. Metals 2003, 137, 973-974. [CrossRef]

35. Sundarrajan, S.; Venkatesan, A.; Ramakrishna, S. Fabrication of nanostructured self-detoxifying nanofiber membranes that contain active polymeric functional groups. Macromol. Rapid Commun. 2009, 30, 1769-1774. [CrossRef] [PubMed]

36. Feng, J.J. The stretching of an electrified non-Newtonian jet: A model for electrospinning. Phys. Fluids 2002, 14, 3912-3926. [CrossRef]

37. Yarin, A.L.; Koombhongse, S.; Reneker, D.H. Bending instability in electrospinning of nanofibers. J. Appl. Phys. 2001, 89, 3018-3026. [CrossRef]

38. Spivak, A.F.; Dzenis, Y.A. Asymptotic decay of radius of a weakly conductive viscous jet in an external electric field. Appl. Phys. Lett. 1998, 73, 30673069. [CrossRef] 
39. Hohman, M.M.; Shin, M.; Rutledge, G.; Brenne, R.M.P. Electrospinning and electrically forced jets. I. Stability theory. Phys. Fluids 2001, 13, 2201-2220. [CrossRef]

40. Hohman, M.M.; Shin, M.; Rutledge, G.; Brenner, M.P. Electrospinning and electrically forced jets II. Applications. Phys. Fluids 2001, 13, 2221-2236. [CrossRef]

41. Feng, J.J. Stretching of a straight electrically charged viscoelastic jet. J. Non-Newton. Fluid Mech. 2003, 116, 55-70. [CrossRef]

42. Reneker, D.H.; Yarin, A.L.; Fong, H.; Koombhongse, S. Bending instability of electrically charged liquid jets of polymer solution in electrospinning. J. Appl. Phys. 2000, 87, 4531-4547. [CrossRef]

43. Yarin, A.L.; Koombhongse, S.; Reneker, D.H. Taylor cone and jetting from liquid droplets in electrospinning of nanofibers. J. Appl. Phys. 2001, 90, 4836-4846. [CrossRef]

44. Fridrikh, S.V.; Yu, J.H.; Brenner, M.P.; Rutledge, G.C. Controlling the fiber diameter during electrospinning. Phys. Rev. Lett. 2003, 90, 144502. [CrossRef] [PubMed]

45. Theron, S.A.; Yarin, A.L.; Zussman, E.; Kroll, E. Multiple jets in electrospinning: Experiment and modeling. Polymer 2005, 46, 2889-21899. [CrossRef]

46. Reneker, D.H.; Yarin, A.L.; Zussman, E.; Xu, H. Electrospinning of nanofibers from polymer solutions and melts. Adv. Appl. Mech. 2007, 41, 43-195.

47. Thompson, C.J.; Chase, G.G.; Yarin, A.L.; Reneker, D.H. Effects of parameters on nanofiber diameter determined from electrospinning model. Polymer 2007, 48, 6913-6922. [CrossRef]

48. Stepanyan, R.; Subbotin, A.; Cuperus, L.; Boonen, P.; Dorschu, M.; Oosterlinck, F.; Bulters, M.J.H. Fiber diameter control in electrospinning. Appl. Phys. Lett. 2014, 105, 173105-173109. [CrossRef]

49. Stepanyan, R.; Subbotin, A.; Cuperus, L.; Boonen, P.; Dorschu, M.; Oosterlinck, F.; Bulters, M.J.H. Nanofiber diameter in electrospinning of polymer solutions: Model and experiment. Polymer 2016, 97, 428-439. [CrossRef]

50. Ismail, N.; Maksoud, F., Jr.; Ghaddar, N.; Ghali, K.; Tehrani-Bagha, A. Simplified modeling of the electrospinning process from the stable jet region to the unstable region for predicting the final nanofiber diameter. J. Appl. Polym. Sci. 2016, 133, 44112. [CrossRef]

51. Peer, P.; Stenicka, M.; Pavlinek, V.; Filip, P. The storage stability of polyvinylbutyral solutions from an electrospinnability standpoint. Polym. Degrad. Stab. 2014, 105, 134-139. [CrossRef]

52. Koski, A.; Yim, K.; Shivkumar, S. Effect of molecular weight on fibrous PVA produced by electrospinning. Mater. Lett. 2004, 58, 493-497.

53. Shenoy, S.L.; Bates, W.D.; Frisch, H.L.; Wnek, G.E. Role of chain entanglements on fiber formation during electrospinning of polymer solutions: Good solvent, nonspecific polymer-polymer interaction limit. Polymer 2005, 46, 3372-3384.

(C) 2019 by the authors. Licensee MDPI, Basel, Switzerland. This article is an open access article distributed under the terms and conditions of the Creative Commons Attribution (CC BY) license (http://creativecommons.org/licenses/by/4.0/). 